http://dx.doi.org/10.30681/23588403v12i038089

\title{
O ENIGMA DA DIFERENÇA: UM INCÔMODO ANTROPOLÓGICO E SOCIAL EM “A MENOR MULHER DO MUNDO”, DE CLARICE LISPECTOR
}

\author{
Adriano de Paula RABELO (UFMG) ${ }^{1}$ \\ Data de recebimento: $30 / 08 / 2018$ \\ Aceite: 05/11/2018
}

\begin{abstract}
Resumo: Este artigo enfoca a dificuldade de reconhecimento e aceitação da alteridade tal como elaborada no conto "A menor mulher do mundo", de Clarice Lispector. Analisa-se os dois âmbitos em que a ação se desenvolve - a selva africana e lares de classe média numa cidade moderna -, inter-relacionando-os com atenção especial para aspectos antropológicos e sociais do tema em estudo. Embora esta história também contenha elementos que remetem à vertente existencial, pela qual a escritora é mais imediatamente reconhecida, o foco de interesse deste ensaio está muito mais na abordagem dos aspectos sociais da narrativa, vertente que terá um desenvolvimento maior na última fase da obra de Clarice Lispector.

Palavras-chave: alteridade, diferença, encontro com o outro, epifania, humanização.
\end{abstract}

Abstract: This article studies the difficulties for recognizing and accepting alterity in the short story untitled "The smallest woman in the world" by Clarice Lispector. There is an analysis of the two spheres where the action takes place - the African jungle and middle class homes in a modern city, relating the episodes that occur in each one of them and focusing their anthropological and social aspects. Although this story also contains the existential aspects by which Lispector is immediately recognized, this essay's core of interest is much more in social aspects of this narrative, a side that will be more widely developed along the last stage of Clarice Lispector's work.

Keywords: alterity, difference, meeting the other one, epiphany, humanization.

Em 1959, Clarice Lispector publicou, na revista Senhor, o breve conto "A menor mulher do mundo", uma história muito inquietante que se mostra bastante atual neste momento em que assistimos ao recrudescimento de ideologias excludentes e a uma enorme dificuldade em lidar com o outro em sua diferença. No ano seguinte o mesmo conto foi publicado na coletânea intitulada Laços de Família.

A história consiste no relato, por parte de um narrador onisciente, do encontro do explorador francês Marcel Pretre, nos confins da África Equatorial, com uma mulher pigmeia "de quarenta e cinco centímetros, madura, negra, calada" (LISPECTOR, 1976, p. 77), bem como da repercussão desse acontecimento em lares de classe média urbana, a partir de reportagens publicadas nos jornais de domingo. Tratava-se da menor mulher do mundo, que

1 Doutor em Literatura Brasileira pela Universidade de São Paulo, professor de Literatura Brasileira na Universidade Federal de Minas Gerais, Belo Horizonte, Brasil, aprabelo@ hotmail.com. 
ainda por cima estava grávida. Eis um prato cheio para o sensacionalismo jornalístico e para a recepção frívola por parte dos leitores dominicais do noticiário. Frívola mas reveladora, como se verá.

No encontro do francês com a nativa das selvas africanas, acontecimento que dá origem ao conto, dois mundos muito distintos e incompreensíveis reciprocamente se veem frente a frente. Suas atitudes são bastante reveladoras de seus universos culturais. O homem europeu moderno sente logo a necessidade de ordenar tudo, de colher dados sobre o ser humano tão excepcional que tem diante de si, de dar-lhe um nome, já que isso é fundamental numa civilização logocêntrica. Assim, chama-a Pequena Flor. Tal nome talvez não seja tão inocente nem tão lírico quanto parece à primeira vista, já que funciona como uma redução da nativa africana à condição vegetal. Essa atitude está em consonância com a visão desumanizadora que historicamente tem marcado o europeu em suas relações com os povos primitivos.

Os dados levantados pelo explorador dão conta de que a menor mulher do mundo pertence à raça dos likoualas, que estão ameaçados de extinção por serem presas bantos, que os caçam com redes e os comem. Por isso se refugiaram no coração da selva, vivendo no topo das árvores mais altas, de onde as mulheres descem para preparar milho, mandioca e verduras, e os homens para caçar. Ainda segundo esses dados, a língua likouala é simples, composta apenas do essencial, fazendo uso de gestos e sons animais. A espiritualidade desse povo se processa ao toque de um tambor. Como defesa contra os bantos, os likoualas mantêm apenas um machado pequeno de prontidão.

$\mathrm{Na}$ segurança da fria racionalidade dessas informações, Pretre contempla Pequena Flor, sentindo a atração fascinada de um cientista por seu objeto de estudo. No entanto, essa atração acabou por se transformar em repulsa no momento em que a pigmeia "coçou-se onde uma pessoa não se coça" (LISPECTOR, 1976, p. 79). Quando isso acontece, ele desvia seus olhos castos e idealistas daquele raríssimo objeto de estudos. Essa castidade e esse idealismo parecem remeter ao sobrenome do explorador, que em francês quer dizer "padre", o que, juntamente com sua postura de superioridade, evoca toda a longa história da dominação colonial europeia, realizada, em grande parte, sob o argumento de expandir a fé cristã.

Naturalmente faz parte da exploração do exótico o registro fotográfico que permitirá à civilização moderna partilhar da experiência incomum vivenciada por alguns de seus representantes em lugares distantes e debater o estranhamento provocado por imagens de uma realidade muitas vezes desconcertante. A imprensa, com sua fixação pelo que foge à "normalidade", é a responsável por trazer a versão jornalística dessas experiências até as 
habitações dos cidadãos modernos. É onde ocorrerá uma espécie de consumo da experiência do exótico pelo crivo dos preconceitos das pessoas "civilizadas", participantes de uma cultura dominante e pretensamente superior.

Se a primeira parte do conto centra-se na figura de Marcel Prete, descrevendo ações reveladoras da figura que ele representa, a segunda, numa brusca mas coerente ruptura, transporta o leitor para casas e apartamentos de uma cidade não nomeada porém representativa de todos os centros urbanos modernos e civilizados do mundo, centrando-se nas pessoas que veem a fotografia de Pequena Flor no jornal. Tais pessoas representam todo um espectro da classe média e da gente "comum” desse ambiente. Diferentes idades (crianças, adolescentes, jovens, adultos e velhos) e diferentes papéis sociais (pai, mãe, filho, irmão, possivelmente uma avó) surgem brevemente em cena, expondo as reações de um grupo representativo de pessoas à imagem da menor mulher do mundo, grávida, publicada nos jornais. É um salto da ambientação primitiva da selva africana para um ambiente que exprime o progresso das nossas cidades. É também um salto do tempo histórico a que o encontro entre Prete e Pequena Flor remete para o tempo social do homem urbano em suas relações e visões de mundo comezinhas.

Que reações o retrato da pigmeia grávida provoca nas casas e apartamentos modernos? Em seis flashes cênicos, o narrador do conto captura os sentimentos de cada receptor da imagem de Pequena Flor com "o nariz chato, a cara preta, os olhos fundos, os pés espalmados" (LISPECTOR, 1976, p. 80). No primeiro deles, somos informados de que uma mulher, vendo-a num jornal aberto, não quis olhar novamente por sentir-se aflita. No segundo, outra mulher é tomada por sentimentos contraditórios: "perversa ternura", “escuridão de amor", "bondade perigosa” (LISPECTOR, 1976, p. 80), passando o resto do dia em estado de perturbação. No terceiro, uma menina de cinco anos sente espanto, pois era até então, em sua casa, "o menor dos seres humanos" (LISPECTOR, 1976, p. 80), o que a conduz a uma primeira e vaga elaboração de uma sabedoria de senso comum, intuindo que "a desgraça não tem limites" (LISPECTOR, 1976, p. 80). No quarto flash, num brevíssimo diálogo entre mãe e filha, ficamos sabendo que "a moça noiva teve um êxtase de piedade" (LISPECTOR, 1976, p. 80) pela tristeza que identifica em Pequena Flor, enquanto a mãe, enrijecida, afirma que aquilo "é tristeza de bicho, não é tristeza humana" (LISPECTOR, 1976, p. 81). No quinto, um menino imagina a possibilidade de pregar uma peça no irmão, colocando a africana em sua cama quando ele estiver dormindo, a fim de assustá-lo ao despertar, para logo depois fazer dela um brinquedo. E a mãe, engajada na civilizada tarefa de 
enrolar os cabelos diante do espelho, recorda-se de uma história macabra que lhe fora contada pela cozinheira da casa. Criada num orfanato, a empregada, juntamente com as outras internas, escondeu a morte de uma das meninas, passando a brincar com o cadáver, dar-lhe banho, comidas e carinho. Isso faz com que a mãe reflita sobre "a cruel necessidade de amar", "a malignidade de nosso desejo de ser feliz", "a ferocidade com que queremos brincar", “o número de vezes em que matamos por amor" (LISPECTOR, 1976, p. 81). Em seguida, olha para o filho, que está em fase de troca de dentes, como se olhasse para "um perigoso estranho" (LISPECTOR, 1976, p. 81), sentindo um misto de terror e orgulho desconfortável. Faz, então, planos de comprar-lhe uma roupa nova e elegante, além de mantê-lo bem limpo, a fim de afastá-lo da animalidade que a imagem da pequena africana representa. Por fim, olhase no espelho do banheiro e constata "a distância insuperável de milênios" (LISPECTOR, 1976, p. 82) que a separa de Pequena Flor. De todo modo, tem consciência de que naquele dia "teria de disfarçar de si mesma a ansiedade, o sonho, e milênios perdidos" (LISPECTOR, 1976, p. 82). Por fim, no sexto flash cênico, em outra casa, uma família se reúne para, com uma fita métrica, medir os $45 \mathrm{~cm}$ daquele ser humano tão grotesco mas tão atraente cuja fotografia fora publicada em tamanho natural no periódico de domingo, espantando-se com seu tamanho e desejando, cada membro do grupo, possuir para si "aquela coisa miúda e indomável, aquela coisa salva de ser comida, fonte permanente de caridade" (LISPECTOR, 1976, p. 82). A mãe chega a imaginá-la servindo a mesa em sua casa, como empregada doméstica. O diálogo, entretanto, termina com uma discussão entre marido e mulher, quando o pai, desconfortável com a menção ao bebê de Pequena Flor, encerra a conversa bruscamente.

Essas cenas mostram o quanto a animalidade, que os modernos citadinos identificam na pigmeia, está presente neles mesmos, o que verdadeiramente se esconde por trás de sua capa de cultura refinada. É a intuição disso que provoca desconforto e mesmo constrangimento nesses seres empanturrados de civilização no momento em que a figura primitiva da mulherzinha likouala faz vir à tona o selvagem que está entranhado nos recônditos de sua psicologia. Além disso, a relação que essas pessoas imaginam poder ter num confronto direto com Pequena Flor reproduz, na esfera doméstica, a experiência etnocêntrica de Pretre, representativa da história secular de dominação e exploração imperialista e colonial europeia. Nesses lares de classe média também se fazem presentes os preconceitos culturais, o desejo de posse do outro, o racismo, a exploração do trabalho dos membros das classes subalternas. Tudo isso sob o verniz de uma ternura cruel várias vezes ressaltada pelo narrador. Uma 
ternura cruel que foi uma das marcas da formação de nossa sociedade patriarcal e que ainda constitui a base da violência que marca as relações entre as classes superiores e inferiores num país como o Brasil. Tais relações aproximam bastante a cidade moderna da floresta primitiva. Na selva urbana, os cidadãos educados, endinheirados e com mais capital social não agem de maneira muito diferente dos bantos que caçam os likoualas com redes para comê-los. Apenas as redes e o comê-los se realizam por meio de formas consideradas "civilizadas". Chama ainda a atenção a forma como os membros das famílias modernas se mostram estranhos uns aos outros, incapazes de reconhecer a própria humanidade de seus pais, filhos e irmãos, interessando-se mais facilmente por realidades exóticas e distantes, também estas desumanizadas exatamente pelo exotismo e a distância.

Em Orientalismo: O Oriente como Invenção do Ocidente, Edward Said analisa como, na hegemonia política, econômica e cultural do Ocidente sobre o Oriente, construiu-se, ao longo dos últimos três séculos, um discurso que reduz a complexidade e a dinâmica oriental a uma essência em geral portadora de traços negativos que devem ser controlados e manipulados. Portanto, no tempo da centralidade mundial da Europa, cabia aos europeus definir o que era o Oriente e construir todo um discurso sobre ele, responsabilidade hoje repassada aos americanos. Obviamente a relação entre essas duas metades do mundo é uma relação de poder ou, mais especificamente, de dominação.

Na mesma linha de Said, talvez se possa falar também de um "africanismo", ou seja, uma elaboração sobre um continente que tem sofrido os efeitos do jogo de poder mundial de forma talvez ainda mais brutal. A postura de Marcel Pretre diante de Pequena Flor é perfeitamente representativa desse jogo de forças. E as reações dos leitores de jornal citadinos à foto da pigmeia, como a reatualizar a metáfora de uma caixa dentro de outra caixa, utilizada no conto, reproduz essa relação no plano do senso comum, expondo a naturalização da perversidade da "objetificação" desse outro desprivilegiado.

Mas ainda há uma terceira parte, quando ocorre outra ruptura no fluxo narrativo e a ação volta a se desenvolver no interior da selva africana. Logo de início o narrador explora a simbologia do negro e da escuridão significando o incompreendido ou o incompreensível. Assim o narrador introduz um episódio em que ficará evidente a incompreensão do explorador francês diante da negra nativa da selva congolesa. Isso porque, enquanto se encaravam, Pequena Flor riu. Esse riso inesperado faz com que Pretre seja tomado por uma sensação de mal-estar. 
O narrador sintetiza o que estava por trás daquele riso constrangedor e inclassificável por parte de um europeu nascido e criado na segurança de sua sociedade avançada:

Estava rindo, quente, quente. Pequena Flor estava gozando a vida. A própria coisa rara estava tendo a inefável sensação de ainda não ter sido comida. (...) Era um riso como somente quem não fala, ri. Esse riso o explorador constrangido não conseguiu classificar. $\mathrm{E}$ ela continuou fruindo o próprio riso macio, ela que não estava sendo devorada. Não ser devorado é o sentimento mais perfeito. Não ser devorado é o objetivo secreto de toda uma vida. Enquanto não estava sendo comida, seu riso bestial era tão delicado como é delicada a alegria. O explorador estava atrapalhado. (LISPECTOR, 1976, p. 84)

O mal-estar do francês já havia sido introduzido quando a africana se coçara onde não se coça. Quando ela ri, porém, cai por terra toda uma série de papéis que sustentam uma pretensa "superioridade" de alguém que é homem, branco, europeu, colonizador, civilizado, moderno e de grande porte diante de alguém que é mulher, negra, africana, colonizada, primitiva, arcaica e pequena. Ironicamente assistimos ao apequenamento do "homem de tamanho grande" (LISPECTOR, 1976, p. 85), que não consegue quantificar aquele riso humanizador que faz da africana, antes reduzida a mero objeto de estudo, um sujeito pleno, capaz inclusive de gozar a vida e o privilégio de existir, mesmo nas condições de perigo permanente em que atravessa a existência.

Mas o narrador vai ainda mais fundo na "grande escuridão [que] pusera-se em movimento" (LISPECTOR, 1976, p. 84) no espírito de Pequena Flor, revelando que seu riso era também uma expressão do que estava sentindo naquele momento: Amor, com inicial maiúscula. Ou seja, um Amor essencial, desprovido de "refinamentos cruéis" (LISPECTOR, 1976, p. 85), amplo a ponto de abarcar não somente a pessoa amada mas também suas coisas e tudo o que lhe diz respeito: "Ela amava aquele explorador amarelo. (...) também amava muito o anel do explorador e (...) amava muito a bota do explorador. (...) nem de longe seu profundo amor pelo explorador ficaria desvalorizado pelo fato de ela também amar sua bota" (LISPECTOR, 1976, pp. 84 e 85).

Um amor como esse vai muito além das formas possessivas, limitadoras e exclusivistas com as quais nós, que estamos próximos do universo cultural de Pretre, costumamos praticar 
e que o narrador considera um equívoco. O amor de Pequena Flor é o de alguém que, nas palavras do mesmo narrador, "estava reduzida à profundeza" (LISPECTOR, 1976, p. 85).

Perturbado ante do riso da pigmeia, o explorador tenta sorrir-lhe de volta, esboçando uma retribuição do gesto amoroso da nativa. Pode-se dizer que é no brevíssimo tempo de duração desse sorriso que esses dois seres humanos tão distantes culturalmente de fato se encontram. Mas esse instante humanizador logo desvanece, pois Pretre de imediato busca se recompor, disfarçando seu incômodo com um ajeitar de chapéu. Cheio de pudor, adquire uma cor de pele "de um rosa-esverdeado, como a de um limão de madrugada. Ele devia ser azedo" (LISPECTOR, 1976, p. 85). Em seguida, retoma os cacoetes de homem civilizado e racional, reconcentrando-se em seu trabalho, voltando a tomar notas, interpretar sinais e fazer perguntas. É novamente o investigador com seu método de trabalho, persona com que ele se sente muito mais seguro. A nativa, por sua vez, não precisa assumir uma persona que lhe dê mais segurança. Em sua espontaneidade, apenas segue fruindo a felicidade de possuir uma árvore para morar.

Nesta cena o narrador nos põe diante do contraste entre a exterioridade científica do europeu, com seu chapéu e seu caderno de notas, e a interioridade da africana, sem esses apetrechos civilizatórios. O coçar onde não se coça de Pequena Flor e seu riso, bem como a tentativa de sorriso e o corar de pudor de Pretre fazem com que ambos verdadeiramente se encontrem naquilo que os seres humanos têm de essencial e que no fundo anula suas diferenças, por maiores que elas sejam: as emoções, os sentimentos, o desejo, os sonhos. Eis o breve momento de epifania tão recorrente na literatura de Clarice Lispector. Essa epifania e seu reconhecimento por parte de nós, leitores, permite que nos reconectemos aos tipos representativos da classe média urbana rapidamente apresentados nos flashes cênicos da segunda parte do conto, com a possibilidade de refletir acerca dos preconceitos, da exclusão do outro desprivilegiado e do desconhecimento que temos inclusive daqueles com quem convivemos muito de perto. As diferenças que nos separam são parte do processo civilizacional que resultou numa organização social tão problemática.

Em O Mal-estar na Civilização, Freud apresenta sua tese de que a sociedade só se tornou possível por meio do sacrifício do indivíduo, que teve de pagar o preço da renúncia à satisfação permanente de suas pulsões em prol da construção de uma comunidade que lhe ofereceria segurança, progresso material e desenvolvimento cultural. No entanto, a cultura acabou por produzir um constante mal-estar nos seres humanos, em virtude do antagonismo intransponível entre as exigências da pulsão e as da civilização. Nosso desafio continua a ser 
como dar vazão adequada a nossas pulsões dentro da civilização, que inegavelmente nos proporcionou a sobrevivência de seres frágeis num mundo tão hostil. Se a cultura da primitiva Pequena Flor possui menos instâncias inibidoras, a do moderno Pretre chega ao ponto de colocá-lo em estado de perturbação diante do aflorar de suas pulsões, fazendo com que ele busque sofregamente safar-se do esboço de uma retribuição à sensualidade do coçar-se da pigmeia, bem como de seu sorriso e seu amor essencial, refugiando-se em seu método científico e ocupando-se logo em tomar notas, muitas notas.

Mas o conto termina de forma enigmática, saltando outra vez para a selva das cidades, onde uma velha senhora, fechando o jornal decididamente, declara após ver a fotografia de Pequena Flor grávida: "pois olhe, eu só lhe digo uma coisa: Deus sabe o que faz" (LISPECTOR, 1976, p. 86). Talvez se possa fazer duas interpretações contraditórias desse "Deus sabe o que faz". Pode ser que, tal como Pretre, que se refugia na ciência, essa senhora também precise de um refúgio em alguma coisa para não sucumbir à escuridão das pulsões, e essa coisa seria a religião. Ou, quem sabe, em sua experiência de mulher idosa, ela esteja chamando a atenção para o que há de enriquecedor no encontro com o outro exatamente por sua diferença, que tudo em Pequena Flor está certo e que ela é digna de respeito pelo fato de sua mera humanidade? São duas leituras possíveis.

Nesta narrativa sem clímax, que em alguns aspectos lembra os contos de Tchekhov, Clarice Lispector desnuda, com grande sutileza, o que está por detrás das relações sociais. E numa quebra da visão romântica das relações amorosas, expõe o quanto ao amor são inerentes a crueldade, a malignidade e a ferocidade. Mesmo depois de milênios de civilização, a animalidade permanece uma dimensão fundamental do homem moderno e civilizado. Isso certamente explica a permanência da violência e da competitividade dos homens em todos os campos de atividade.

Nesta história, Clarice desvela toda a crueldade dos mecanismos sociais de exclusão e exploração do outro, as hipocrisias justificadoras dessas barbaridades, o preconceito racial e o preconceito social softcore mas muito reveladores, tal como estamos acostumados a testemunhá-los no Brasil.

A propósito, esses preconceitos "cordiais" típicos do homem brasileiro algumas vezes em nossa história resultou em grandes catástrofes. Para ficar apenas num exemplo, basta mencionar o episódio de Canudos, que colocou em confronto a elite litorânea, eivada de republicanismo, europeísmo e toda a arrogância de quem estava certo de sua superioridade, e a massa de seguidores do beato Antônio Conselheiro, considerada atrasada, ignorante e 
fanática. Naquela guerra, o litoral supostamente civilizado barbarizou o sertão primitivo por meio de nosso exército, numa das páginas mais vergonhosas da história do Brasil. Ficou então claro que a elite litorânea tinha com o interior do país uma relação muito semelhante à que as potências colonialistas tiveram com os lugares que subjugaram, inclusive em seu terrível modus operandi.

E para não deixar de mencionar também uma barbaridade contemporânea - que a classe média também recebe pelo noticiário em seus lares localizados nos bons bairros de nossas cidades -, basta lembrar dos milhares de cadáveres de jovens negros que são assassinados a cada ano nas periferias dessas mesmas cidades, em bairros com péssima infraestrutura. Parte significativa dessas mortes são causadas pela polícia. Portanto, são assassinatos realizados por representantes do Estado e financiados com dinheiro público. Isso nos dá uma ideia da "perversa ternura", da "escuridão de amor", da "bondade perigosa" com as quais navegamos socialmente a cada dia.

Em "A menor mulher do mundo", num primor de concisão e densidade expressiva, Clarice Lispector enfatiza o quanto, para além de seres sociais, somos essencialmente seres pulsionais. Faz isso, porém, mostrando como nossas pulsões afloram no embate com a diferença no próprio processo social, na interação com uma alteridade que nos é quase sempre incômoda. Essa vertente social da autora, que teve suas primeiras mas ainda tímidas formulações no final dos anos 1950, será desenvolvida em maior extensão e de modo mais evidente em meados dos anos 1970, muito especialmente em A Hora da Estrela. Esse, que será o último livro de Clarice, confronta, pelas ruas do Rio de Janeiro, a vida miserável da migrante nordestina Macabea com as elucubrações literárias do escritor Rodrigo S.M., que, num passeio pelas ruas, capta o olhar desesperado da moça, de quem contará a existência como tentativa de se livrar do mal-estar nele provocado pelo conhecimento da marginalização a que está reduzida uma grande parte da população da cidade grande.

Como se viu, a abordagem social de Clarice Lispector passa longe de certa literatura que se limita a denunciar as mazelas de nossa sociedade. Em vez de induzir o leitor a uma fácil indignação com a exclusão e a segregação em que vive um número significativo de pessoas entre nós, em sua obra os problemas sociais estão sempre entrelaçados a questões existenciais. Ao mergulhar na subjetividade humana para tentar entender a nossa natureza, a autora quase sempre leva seus personagens e também o leitor à experiência de uma epifania, ainda que muitas vezes a revelação epifânica decorra da náusea. Como se percebe, há um marcante substrato existencialista em toda a narrativa social de Clarice Lispector. 


\section{Referências}

BARBOSA, Maria José Somerlate. Clarice Lispector: des/fiando as teias da paixão. Porto Alegre: Edipucrs, 2001.

BORELLI, Olga. Clarice Lispector: esboço para um possível retrato. Rio de Janeiro: Nova Fronteira, 1981.

CASTILHO, Angélica de Oliveira. Clarice Lispector e Nelson Rodrigues: modernidade e tragicidade (Tese de Doutorado). Rio de Janeiro: Universidade Federal do Rio de Janeiro, 2006.

CIXOUS, Hélène. A hora de Clarice Lispector. Rio de Janeiro: Exodus, 1999.

FREUD, Sigmund. O mal-estar na civilização. São Paulo: Penguin Companhia, 2011.

GOTLIEB, Nádia Battella. Clarice: uma vida que se conta. São Paulo: Ática, 1995.

. Clarice fotobiografia. São Paulo: Edusp, 2013.

HOSKEN, Geuza Machado. Clarice Lispector: a trama da diferença (Tese de Doutorado). Rio de Janeiro: Universidade Federal do Rio de Janeiro, 1989.

LISPECTOR, Clarice. Laços de família. Rio de Janeiro: José Olympio, 1976.

MOSER, Benjamin. Clarice, uma biografia. São Paulo: Cosac Naify, 2011.

PONTIERI, Regina (Org.). Leitores e leituras de Clarice Lispector. São Paulo: Hedra, 2004.

ROUANET, Sérgio Paulo. O mal-estar na modernidade. São Paulo: Companhia das Letras, 1993.

SAID, Edward. Orientalismo: o Oriente como invenção do Ocidente. São Paulo: Companhia das Letras, 2001.

SANT'ANNA, Affonso Romano de e COLASANTI, Marina. Com Clarice. São Paulo: Editora Unesp, 2013.

VÁRIOS AUTORES. Clarice Lispector: Cadernos de Literatura Brasileira. São Paulo: Instituto Moreira Salles, 2004.

WALDMAN, Berta. "Duas mulherzinhas". In: Entre passos e rastros: presença judaica na literatura brasileira. São Paulo: Perspectiva, 2001, pp. 63-72. 